\title{
Short-term change in self-reported COPD symptoms after smoking cessation in an internet sample
}

\author{
J-F. Etter
}

ABSTRACT: Smoking is the first risk factor for chronic obstructive pulmonary disease (COPD). Some recent reports suggest that, unexpectedly, some respiratory symptoms may increase transiently after smoking cessation, but there is a dearth of short-term data to test this hypothesis. The aim of the present study was to assess the validity of an online screening tool and to describe short-term associations between smoking behaviour and self-reported respiratory symptoms, in cross-sectional and longitudinal data.

An internet survey was conducted in 2003-2009, on a smoking cessation website, with a followup survey after 30 days.

There were 15,916 participants at baseline and 1,831 at follow-up. In the 252 baseline smokers who had quit smoking at 30-day follow-up, there was a substantial decrease in the proportion of participants who declared that they often coughed even without a cold (from $51.6 \%$ at baseline to $15.5 \%$ at follow-up), expectorated when they coughed in the morning (from $47.6 \%$ to $19.4 \%$ ), were out of breath after climbing stairs or after a quick walk (from $75.0 \%$ to $48.4 \%$ ), and who had a wheezing respiration (from $33.7 \%$ to $10.3 \%$ ) ( $p<0.001$ for all before/after comparisons). In participants who did not change their smoking behaviour between assessments, the test-retest reliability was $r=0.87$ for a score summing these four symptoms.

Smoking cessation was followed by a rapid and substantial improvement in self-reported respiratory symptoms. COPD is largely underdiagnosed and undertreated. Internet screening is reliable and may allow for the early detection of COPD symptoms at a large scale, in patients who may otherwise have no access to COPD case-finding efforts.

KEYWORDS: Internet, smoking, tobacco use disorder

hronic obstructive pulmonary disease (COPD) is a major public health problem, and the number of COPD patients is increasing worldwide. In the UK, $13 \%$ of the population over the age of 35 have spirometrydefined COPD [1], most (73\%) COPD deaths are attributable to smoking and COPD mortality accounts for $4.8 \%$ of the total mortality [2].

\section{Effect of quitting smoking on respiratory symptoms}

Smoking cessation is the most effective way to prevent COPD and to alter its progression, at any stage of the disease [3]. The long-term benefits of smoking cessation on COPD are well documented [4-6], but recent literature reviews found surprisingly few studies on the short-term (i.e. after a few days or weeks) effects of smoking cessation on respiratory symptoms [7, 8]. Furthermore, the few available short-term studies were often conducted in small samples and some of them are decades old [8]. Older studies may not reflect the current situation, as cigarette consumption among smokers and the composition of cigarettes has changed substantially in the past decades [9, 10]. The few available short-term studies show that respiratory symptoms (cough, expectoration, breathlessness and wheezing) improve in the first days and weeks after smoking cessation $[8,11,12]$. However, increased coughing has been described anecdotally as a cigarette withdrawal symptom [7], and a recent study also suggests that cough and common cold symptoms may increase transiently after smoking cessation [13], an effect that could be explained by a reduction in secretory immunoglobulin A [14]. In spite of the dearth of shortterm data, both the International Classification of Diseases (ICD-10) and the Diagnostic and Statistical Manual of Mental Disorders (DSMIV) list increased cough among tobacco or nicotine withdrawal symptoms. There is a need
CORRESPONDENCE

J-F. Etter

Institute of Social and Preventive

Medicine

University of Geneva

CMU

1 rue Michel-Servet

CH-1211 Geneva 4

Switzerland

E-mail: Jean-Francois.Etter@

unige.ch

Received:

June 082009

Accepted after revision:

Oct 132009

First published online:

Nov 192009 
for more short-term data to resolve this apparent contradiction. Also, as the DSM-V and ICD-11 are under development, it is important to document whether or not increased cough is a tobacco or nicotine withdrawal symptom.

\section{Screening for COPD}

Spirometry is essential to the diagnosis of COPD, but it is not always available in primary care settings, and even when it is available, spirometry is often underused [15]. As a result, COPD is largely underdiagnosed, and only $47 \%$ of people with severe COPD report any diagnosed respiratory disease [1]. COPD symptoms may remain unnoticed and considered normal by patients (e.g. smoker's cough), who may not present to their doctor until they have severe, irreversible symptoms [15]. Wider case finding efforts are necessary, but screening the general population with spirometry, although it has been done [16], is costly and is unlikely to be widely adopted. Questionnaire screening may be a cost-effective way to select patients eligible for spirometry, but a 2005 review found surprisingly few validated COPD questionnaires [15], and few other questionnaires have been published since this review [17-19]. These studies show that questionnaire screening is useful and feasible in clinical practice, but COPD screening questionnaires have not been tested on the internet. However, COPD screening over the internet may reach large numbers of patients and may allow for the early detection and referral for clinical assessment and spirometry, thereby improving patients' prognosis. Online screening tools are available $24 \mathrm{~h}$ a day, at no charge to participants, even in rural or deprived areas where patients may otherwise have no access to COPD screening. Online screening may be particularly useful and cost-effective in low- or middle-income countries, e.g. China, which is the country with the largest number of internet users, and where smoking prevalence is very high among males [20, 21]. Online COPD screening questionnaires need to be brief and written in simple language, criteria that some of the available COPD questionnaires may not fulfil. However, before internet screening can be recommended, there is a need to test the validity of this approach.

The motivational impact of testing for respiratory symptoms In addition to allowing for early detection of COPD and referral for spirometry, COPD screening questionnaires are also useful as motivational tools. Smokers are more motivated to stop smoking if they realise that their respiratory problems are caused by smoking rather than by other causes [22], and if they believe that health gains will result from quitting smoking [23].

\section{Aim}

Thus, the aims of this study were to assess the feasibility and validity of internet-based COPD screening, and to describe short-term associations between self-reported respiratory symptoms and smoking status.

\section{METHODS}

\section{Participants}

Participants were visitors of the smoking cessation website Stop-tabac.ch, aged $18 \mathrm{yrs}$ or more [24]. We posted the questionnaire, in French, between September 2003 and March 2009 , on this website. A link to the questionnaire was posted on several pages of the website, which was visited by $>80,000$ people per month [24]. During much of the data collection period, the survey was listed third in Google.ch when typing "BPCO" (French for COPD). From August 2005 onwards, participants who agreed and who indicated an e-mail address were invited by e-mail to answer the same survey again, after 30 days.

\section{Questionnaire content}

The questionnaire covered age and sex, whether participants smoked tobacco or cannabis daily or occasionally (not daily), or whether they were former smokers or never smokers. Current smokers indicated the number of cigarettes they smoked per day and the time (minutes) to their first cigarette of the day, both indicators of addiction [25]. Former smokers indicated the date when they had quit smoking. We used a brief questionnaire recommended by the Swiss Pulmonary League to assess COPD symptoms [26]. Participants answered (yes or no) the following questions: "Do you often cough even without a cold?", "Do you expectorate when you cough in the morning?", "Are you out of breath after an effort like climbing stairs or a quick walk?", "Do you have a wheezing respiration?", and "Did you ever have asthma diagnosed?". We computed a $0-4$ sum score, counting 1 point for each symptom (cough, expectoration, breathlessness and wheezing). These four symptoms, in particular expectorating without a cold, are good indicators of COPD [17]. We used a yes/no response format because previous research showed that for respiratory symptoms, multiple response options add only marginal discriminatory power over a yes/no response format [19]. In clinical and internet settings, the simplicity of the yes/no response format outweighs any minor advantage of multiple response formats. We also recorded participants' computer numbers and internet protocol addresses to identify duplicate records. Participants were informed that their answers were stored on a computer file and given the option of declining to have their answers retained on file.

\section{Validity of the data}

Three criteria of data validity were considered: the percentage of missing answers, test-retest reliability and construct validity, reflected by the ability of the questionnaire to detect expected effects (e.g. change over time). We used intraclass correlation coefficients to assess test-retest reliability of individual symptoms and of the 0-4 sum score. We assessed whether reliability coefficients were above the recommended threshold of 0.7 [27]. The test-retest analysis was performed only in the 428 participants in whom we hypothesised that symptom levels would be stable over time: the 266 daily smokers who did not change their cigarette consumption by $>10 \%$ between baseline and follow-up; and the 162 former smokers who had quit smoking $>365$ days before baseline and were still ex-smokers at follow-up.

\section{Associations between smoking status and respiratory symptoms}

In cross-sectional data, we tested whether respiratory symptoms differed between current, former and never smokers. In daily smokers, we tested whether respiratory symptoms were associated with cigarettes smoked per day and with time to the first cigarette of the day. In former smokers, we tested whether 
respiratory symptoms were associated with duration of abstinence.

In longitudinal data, we hypothesised that, after 30 days, respiratory symptoms would: 1) improve in the 252 baseline daily smokers who had quit smoking at the time of the 30-day survey, compared with the 266 daily smokers who did not change their cigarette consumption by $>10 \%$ between baseline and follow-up, in whom we hypothesised that symptoms would remain stable; 2) improve in the 34 baseline smokers who had ever had asthma diagnosed and who had quit smoking at follow-up [28]; and 3) improve in the 220 baseline recent quitters who quit smoking $<31$ days before baseline and were still ex-smokers at follow-up, compared with the 162 people who quit smoking $>365$ days before baseline and were still ex-smokers at follow-up, in whom we hypothesised that symptoms would remain stable.

\section{Statistical analyses}

We used Chi-squared tests to compare proportions, ANOVA F-tests to compare means, and Mann-Whitney U-tests to compare medians. We used McNemar tests to assess change over time in respiratory symptoms, within groups [27]. To assess between-group differences in change over time, we computed a follow-up minus baseline score for each symptom and used Chi-squared tests to compare groups on these difference scores. We used linear regression models to assess associations between continuous variables, with and without adjustment for age, sex and asthma diagnosis (since these variables were associated with respiratory symptoms).

\section{RESULTS}

\section{Participation}

After deletion of 1,437 duplicate records (8.3\% of the 17,353 records in the raw database), there remained 15,916 participants at baseline, of whom $4,668(47.0 \%$ of the 9,927 who answered after August 2005, that is, after we started to collect e-mail addresses) agreed to take part in the follow-up survey and indicated an e-mail address (fig. 1). Of these, 1,831 (39.2\% of 4,665$)$ answered the 30-day survey. Baseline participants

\begin{tabular}{|c|c|c|c|}
\hline & \multicolumn{2}{|c|}{17,353 records } & \\
\hline & \multicolumn{2}{|c|}{ 1,437 duplicate (deleted) } & \\
\hline & \multicolumn{2}{|c|}{15,916 valid records } & \\
\hline & \multicolumn{2}{|c|}{$\begin{array}{l}\text { 9,927 after August } 2005 \\
\text { (start of follow-up) }\end{array}$} & \\
\hline & \multicolumn{2}{|c|}{$\begin{array}{c}\text { 1,831 answered the } \\
\text { 30-day survey }\end{array}$} & \\
\hline $\begin{array}{l}935 \text { baseline } \\
\text { daily smokers }\end{array}$ & \multicolumn{2}{|c|}{$\begin{array}{c}48 \text { occasional smokers, } \\
14 \text { never-smokers, } \\
7 \text { missing }\end{array}$} & $\begin{array}{l}827 \text { baseline } \\
\text { former smokers }\end{array}$ \\
\hline \multicolumn{2}{|l|}{$\nabla$} & & $\downarrow$ \\
\hline \multicolumn{2}{|c|}{$\begin{array}{l}252 \text { quit smoking at follow-up, } \\
683 \text { still smoking, of whom } 266 \\
\text { did not change cigarettes } \\
\text { smoked per day }>10 \%\end{array}$} & \multicolumn{2}{|c|}{$\begin{array}{c}713 \text { still ex-smokers at follow- } \\
\text { up, of whom } 220 \text { had quit } \\
\text { smoking }<31 \text { days before } \\
\text { baseline, } 162 \text { quit }>365 \text { days } \\
\text { before baseline }\end{array}$} \\
\hline
\end{tabular}

FIGURE 1. Flow chart of study participants. were 35 yrs old (median), 47\% were males, 69\% were daily smokers, $4 \%$ were occasional (nondaily) smokers, $24 \%$ were former smokers and $4 \%$ had never been smokers. An asthma diagnosis was reported by $14.2 \%$ of participants. Daily smokers smoked 18 cigarettes per day and they smoked their first cigarette within 23 min of waking up (medians). Former smokers had quit smoking 65 days (median) before the baseline survey (25th and 75th percentiles: 13 and 386 days). The follow-up survey was answered 31 days (median) after baseline (25th and 75th percentiles: 30 and 34 days). Compared with those who did not take part in the 30-day follow-up survey, those who answered this survey were older and more likely to be females and former smokers, and they were slightly less likely to report respiratory symptoms (table 1).

\section{Validity}

For the four questions on respiratory symptoms, there were $0.4-1.3 \%$ missing answers. There were $1.5 \%$ missing answers to the question on asthma. The test-retest intraclass correlation coefficients were $r=0.87(95 \%$ CI $0.85-0.90)$ for the $0-4$ sum score, $\mathrm{r}=0.80(95 \%$ CI $0.75-0.83)$ for cough without a cold, $\mathrm{r}=0.76(95 \%$ CI $0.71-0.80)$ for expectorating in the morning, $\mathrm{r}=0.78(95 \%$ CI $0.73-0.82)$ for breathlessness, and $\mathrm{r}=0.76(95 \%$ CI $0.71-0.80)$ for wheezing.

\section{Cross-sectional analysis}

Respiratory symptoms were higher in daily smokers than in occasional, former and never smokers, but the prevalence of respiratory symptoms was high in all groups (table 2). In daily smokers, there was a linear dose-response association between the number of cigarettes smoked per day and the presence of respiratory symptoms $(+0.32$ symptoms for each additional 10 cigarettes per day, 95\% CI 0.30-0.34; $\mathrm{p}<0.001$ ). This association was only slightly modified after adjustment for age, sex and asthma $(+0.31$ symptoms per 10 cigarettes per day, $95 \% \mathrm{CI}$ $0.29-0.34 ; \mathrm{p}<.001)$. Compared with smokers of $1-9$ cigarettes per day, about twice as many smokers of $\geqslant 25$ cigarettes per day reported each symptom (table 3 ). Most smokers of $\geqslant 25$ cigarettes per day reported cough without a cold $(62.0 \%)$, expectorating in the morning $(57.9 \%)$ and breathlessness $(82.6 \%)$. In daily smokers, there was an inverse linear association between the time (in minutes) to the first cigarette of the day and the number of respiratory symptoms (0-5 min: 2.5 symptoms; 6-30 $\mathrm{min}: 2.0$ symptoms, 31-60 $\mathrm{min}: 1.8$ symptoms; $\geqslant 61$ min: 1.5 symptoms; $F=149.7, p<0.001)$.

In former smokers, the duration of abstinence was strongly, negatively associated with the presence of all four symptoms. For instance, twice as many recent quitters who had quit 0 7 days before baseline reported cough and expectoration, compared with former smokers who had quit 92-365 days ago (table 4). Respiratory symptoms were less frequent in recent quitters who had quit smoking $0-7$ days before baseline than in daily smokers (Chi-squared $\geqslant 7.6$ and $p \leqslant 0.006$ for between-group differences in all four symptoms).

\section{Longitudinal analysis}

Quitters

At 30-day follow-up, 27.0\% (252 out of 935) of baseline smokers had quit smoking. In these 252 quitters, the median duration of abstinence at follow-up was 31 days (25th and 75 th percentiles: 
TABLE 1 Comparison of participants and nonparticipants in the 30-day follow-up survey

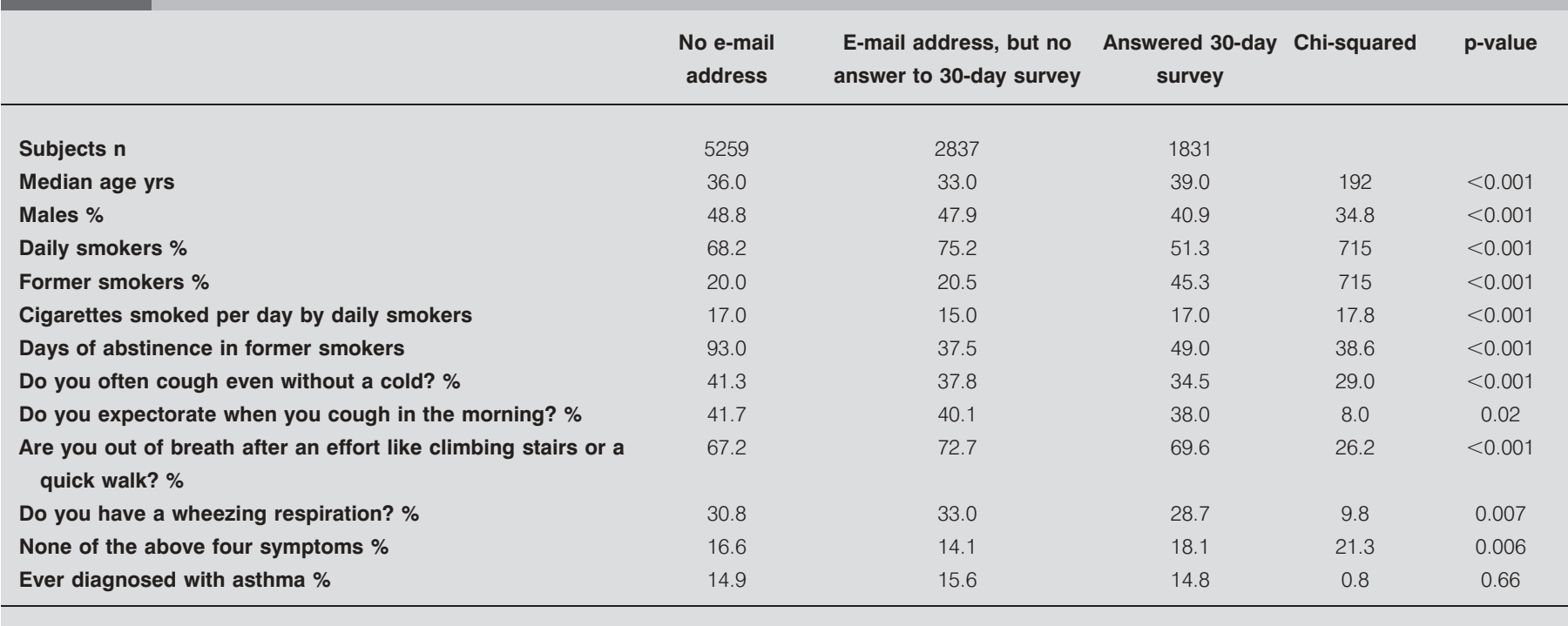

20 and 35 days). In quitters, all respiratory symptoms improved substantially between baseline and follow-up, as hypothesised (table 5). The between-group difference in change over time in respiratory symptoms between recent quitters and continuing smokers was statistically significant $(\mathrm{p} \leqslant 0.003)$ for all symptoms (table 5$)$. The total number of symptoms (0-4 sum score) decreased in $61.5 \%$ of recent quitters, remained stable in $31.7 \%$ and increased in $6.8 \%$ of them. Of the 252 quitters, 34 had ever had asthma. In this subgroup, all respiratory symptoms improved after smoking cessation (cough: from $67.6 \%$ at baseline to $35.3 \%$ at follow-up, $\mathrm{p}=0.01$; expectoration: from $70.6 \%$ to $38.3 \%, \mathrm{p}=0.007$; out of breath: from $91.2 \%$ to $58.8 \%, \mathrm{p}=0.001$; wheezing: from $76.5 \%$ to $32.4 \%, \mathrm{p}<0.001)$.

\section{Recent quitters versus long-term former smokers}

In the 220 recent quitters who had quit $<31$ days before baseline and who remained ex-smokers at 30-day follow-up, all respiratory symptoms improved over time, as hypothesised, whereas in the 162 long-term ex-smokers (who had quit $>365$ days before baseline), respiratory symptoms remained stable. The differences in change over time between these two groups were statistically significant for all symptoms (table 6).

\section{DISCUSSION}

Our results have two broad types of implications. First, they document that online screening for COPD symptoms is feasible at a low cost in very large samples and can produce data of good quality. We assessed three criteria of validity: 1) we showed that these items produced very few missing data: 2) we showed that test-retest reliability was high for the $0-4$ sum score and adequate for the four individual items; and 3) by showing that brief, simple questions on respiratory symptoms are sensitive to change over time in smoking behaviour, our data provide a test of construct validity for this questionnaire [27]. These results suggest that this questionnaire can be a valid and reliable COPD screening tool, used either online, to detect at-risk patients and refer them for clinical assessment, or in clinical practice, to select patients eligible for spirometry. A brief COPD questionnaire can also be used to teach smokers and make them aware that their symptoms are not normal, can be a sign of COPD and are

TABLE 2 Respiratory symptoms at baseline in daily, occasional, former and never-smokers

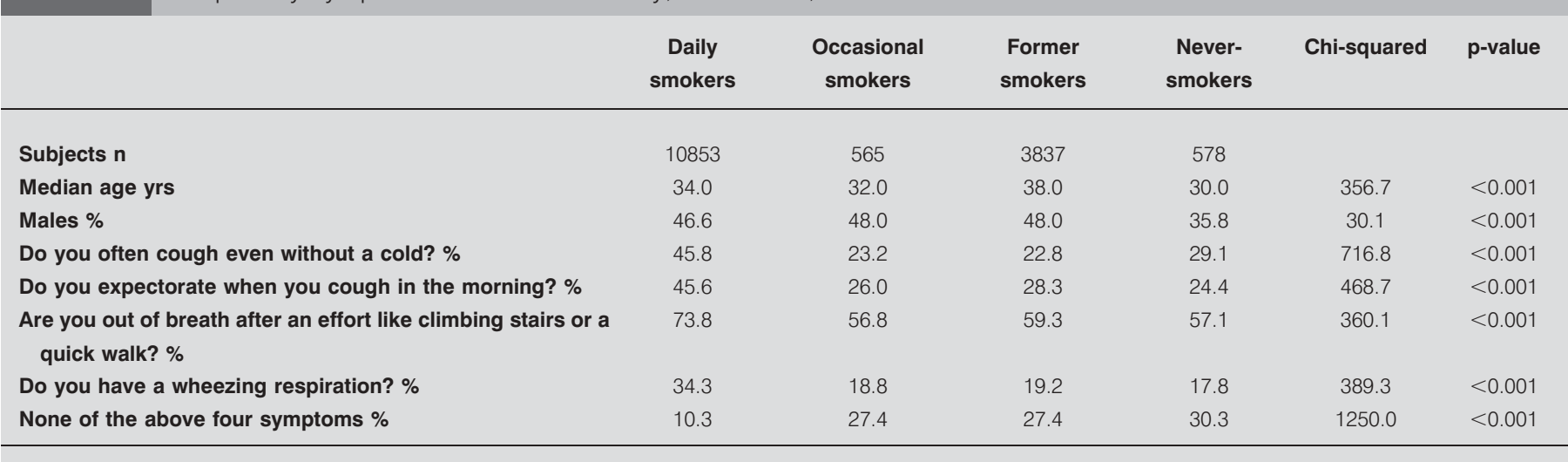


TABLE 3 Respiratory symptoms in daily smokers, by number of cigarettes smoked per day

\begin{tabular}{|c|c|c|c|c|c|c|}
\hline & \multicolumn{4}{|c|}{ Cigarettes per day } & \multirow[t]{2}{*}{ Chi-squared } & \multirow[t]{2}{*}{ p-value } \\
\hline & $1-9$ & $10-19$ & $20-24$ & $\geqslant 25$ & & \\
\hline Subjects $n$ & 1432 & 4056 & 2750 & 2236 & & \\
\hline Median age yrs & 30.0 & 31.5 & 35.0 & 40.0 & 639.7 & $<0.001$ \\
\hline Males \% & 41.7 & 41.9 & 49.0 & 54.1 & 109.1 & $<0.001$ \\
\hline $\begin{array}{l}\text { Are you out of breath after an effort like climbing stairs or a quick } \\
\text { walk? \% }\end{array}$ & 57.8 & 72.1 & 77.9 & 82.6 & 311.0 & $<0.001$ \\
\hline Do you have a wheezing respiration? $\%$ & 23.7 & 28.9 & 36.9 & 47.1 & 294.5 & $<0.001$ \\
\hline None of the above four symptoms \% & 22.8 & 11.3 & 7.6 & 4.2 & 921.1 & $<0.001$ \\
\hline
\end{tabular}

probably due to smoking. This information can motivate smokers to quit $[16,22,23]$.

Secondly, this is one of relatively few studies documenting the short-term effects of smoking cessation on respiratory symptoms [7, 8]. In cross-sectional data, in former smokers, respiratory symptoms were strongly, inversely associated with the duration of abstinence, but this association may not be necessarily causal, because usually only the less addicted smokers (those who may also, on average, have less severe respiratory symptoms) reach long-term abstinence. However, in longitudinal data, quitting smoking was rapidly followed by a substantial improvement in cough, expectoration, breathlessness and wheezing. Thus, our results disagree with the ICD-10 and DSM-IV definition of nicotine/tobacco withdrawal. They also disagree with recent data showing that there is a short-term deterioration in cough and cold symptoms after smoking cessation [13, 14], and with the common but anecdotal belief that cough increases after smoking cessation [7]. In contrast, our results are in agreement with the few previous short-term studies reporting an improvement in cough and other respiratory symptoms in the first days or weeks after smoking cessation $[8,11,12]$, including in patients with asthma [28]. Even though, on average, respiratory symptoms improved substantially after smoking cessation, the number of symptoms increased in a minority $(6.8 \%)$ of quitters, which may explain the occasional observation that these symptoms increase after smoking cessation [7, 13].

\section{Study strengths and limitations}

Our data collection procedure, based on the self-selection of visitors to a smoking cessation website and on a Google link, probably selected people concerned about COPD and resulted in a sample with a high prevalence of smoking and of respiratory symptoms. The prevalence of cough and expectoration was higher in our sample $(>45 \%$ in smokers) than in the general population of smokers $(10-40 \%)$ [8], and the prevalence of asthma was also higher in our sample (14\%) than in the general population ( $\sim 10 \%$ in Europe) [29]. Furthermore, participants were somewhat young (median age $35 \mathrm{yrs}$ ) for an assessment of COPD. Thus, our results may not be generalisable to other populations, and this study should not be interpreted as a prevalence study. However, our aim was not to produce prevalence estimates, but to assess the validity of online COPD screening and to test associations between smoking and respiratory symptoms in the short term. Studies in representative samples are still necessary because of the paucity of short-term longitudinal data on this topic, and because of the small size of many previous samples [7, 8]. Even though it resulted in a selected sample, the internet-based data

TABLE 4 Respiratory symptoms in recent quitters at baseline, by interval since the quit date

\begin{tabular}{|c|c|c|c|c|c|c|}
\hline & \multicolumn{4}{|c|}{ Day since smoking cessation } & \multirow[t]{2}{*}{ Chi-squared } & \multirow[t]{2}{*}{ p-value } \\
\hline & $0-7$ & 8-31 & $32-91$ & 92-365 & & \\
\hline Subjects $n$ & 440 & 563 & 537 & 550 & & \\
\hline Median age yrs & 32.0 & 35.0 & 38.0 & 39.0 & 123.8 & $<0.001$ \\
\hline Males \% & 35.0 & 41.4 & 47.5 & 49.5 & 25.8 & $<0.001$ \\
\hline Do you often cough even without a cold? \% & 34.1 & 24.0 & 13.8 & 14.9 & 78.1 & $<0.001$ \\
\hline Do you expectorate when you cough in the morning? \% & 36.8 & 30.9 & 21.0 & 20.4 & 46.9 & $<0.001$ \\
\hline $\begin{array}{l}\text { Are you out of breath after an effort like climbing stairs or a quick } \\
\text { walk? \% }\end{array}$ & 68.0 & 63.8 & 52.9 & 54.5 & 32.3 & $<0.001$ \\
\hline Do you have a wheezing respiration? \% & 25.2 & 16.3 & 14.9 & 14.9 & 23.3 & $<0.001$ \\
\hline None of the above four symptoms $\%$ & 17.0 & 21.5 & 34.6 & 34.4 & 117.2 & $<0.001$ \\
\hline
\end{tabular}




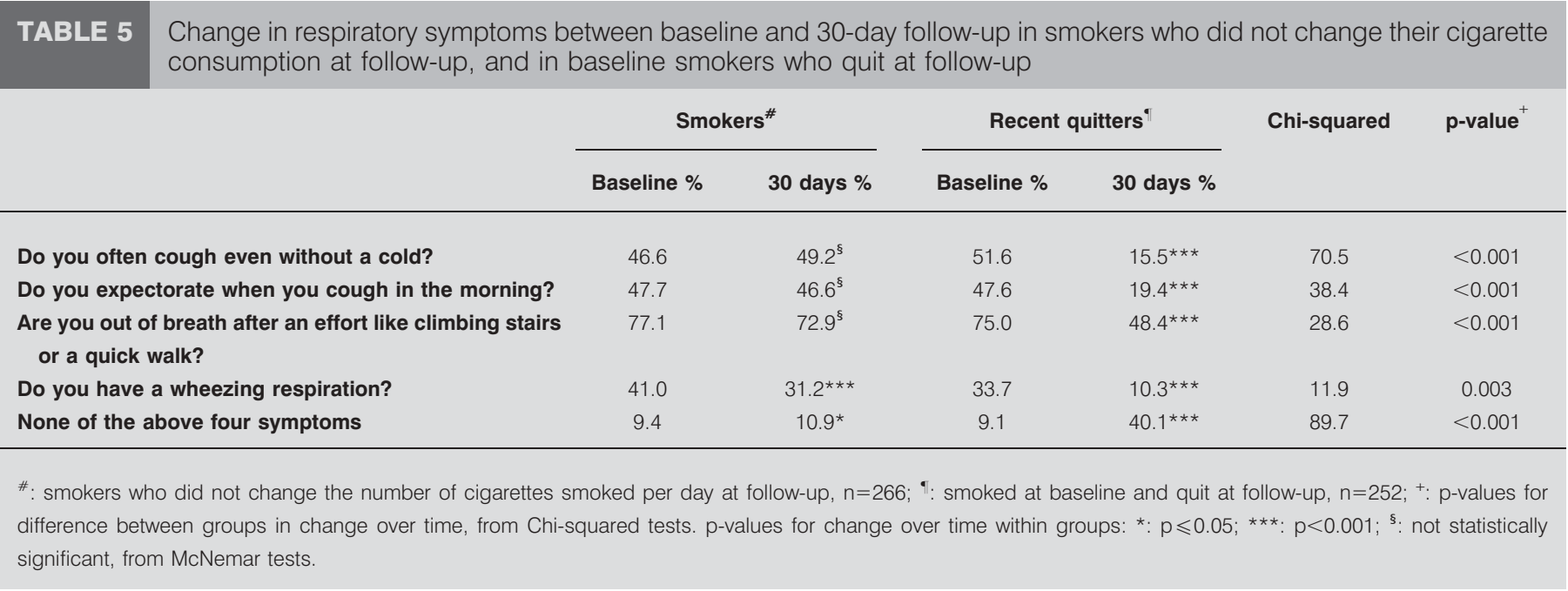

collection was a very effective (and cost-effective) way to enrol one of the largest longitudinal samples described to date in a study of smoking and respiratory symptoms.

The response rate at follow-up (39.2\%) was relatively low, but close to the average response rate of $39.6 \%$ observed in a metaanalysis of internet surveys [30]. Participants in the follow-up survey differed from nonparticipants. This may limit the generalisability of the longitudinal analysis, but it does not affect the validity of this analysis. Collecting follow-up data after 30 days ensured that we captured the short-term effects of smoking cessation, but all the benefits of smoking cessation on respiratory symptoms do not materialise after such a short interval, and these effects can only be documented in longterm data. At follow-up, the average duration of abstinence in recent quitters was 31 days, which may have been too long to detect very short-term effects (e.g. a peak in cough 2-3 days after quitting). Studies with very short follow-ups would be necessary to detect these effects.

Another limitation of this study is that we conducted a limited set of validity tests only. Further tests of construct validity would be useful. Ideally, tests of sensitivity and specificity should also be conducted, with a clinical diagnosis of COPD as the reference, and results should be compared with the performance of other COPD screening questionnaires $[15,17-$ $19,31]$.

\section{Conclusion}

Respiratory symptoms improved substantially and rapidly after smoking cessation. This information can be used to motivate smokers to quit. The currently published data are probably not sufficient to justify the inclusion of increased cough as an ICD-10 and DSM-IV criterion of tobacco or nicotine withdrawal. Our data also suggest that, based on a very brief and simple questionnaire, screening for COPD on the internet is feasible and can detect, at a low cost, very large numbers of COPD patients who may otherwise not have access to COPD screening. COPD is largely underdiagnosed and undertreated [1], and internet screening may contribute to the early detection of COPD on a large scale, and to the subsequent improvement of prognosis in many patients. This could represent a significant public heath advance.

\begin{tabular}{|c|c|c|c|c|c|c|}
\hline & \multicolumn{2}{|c|}{$\begin{array}{l}\text { Ex-smokers who had quit } \\
<31 \text { days before baseline }{ }^{\#}\end{array}$} & \multicolumn{2}{|c|}{$\begin{array}{l}\text { Ex-smokers who had quit } \\
>365 \text { days before baseline }\end{array}$} & \multirow[t]{2}{*}{ Chi-squared } & \multirow[t]{2}{*}{ p-value ${ }^{+}$} \\
\hline & Baseline \% & 30 days $\%$ & Baseline \% & 30 days $\%$ & & \\
\hline $\begin{array}{l}\text { Are you out of breath after an effort like climbing the } \\
\text { stairs or a quick walk? }\end{array}$ & 67.5 & $48.0^{* * *}$ & 56.2 & $58.0^{\S}$ & 33.4 & $<.001$ \\
\hline Do you have a wheezing respiration? & 19.9 & $5.1^{* * *}$ & 17.8 & $16.6^{\S}$ & 15.9 & $<.001$ \\
\hline None of the above four symptoms & 19.5 & $42.3^{* * *}$ & 38.5 & $34.9^{\S}$ & 62.8 & $<.001$ \\
\hline
\end{tabular}




\section{STATEMENT OF INTEREST}

None declared.

\section{ACKNOWLEDGEMENTS}

V. Baujard, from the Health on the Net Foundation (Geneva, Switzerland; www.hon.ch), developed the software for data collection.

\section{REFERENCES}

1 Shahab L, Jarvis MJ, Britton J, et al. Prevalence, diagnosis and relation to tobacco dependence of chronic obstructive pulmonary disease in a nationally representative population sample. Thorax 2006; 61: 1043-1047.

2 Peto R, Lopez AD, Boreham J, et al. Mortality from Smoking in Developed Countries 1950-2000. Oxford, Oxford University Press, 2006

3 Godtfredsen NS, Vestbo J, Osler M, et al. Risk of hospital admission for COPD following smoking cessation and reduction: a danish population study. Thorax 2002; 57: 967-972.

4 Pisinger C, Godtfredsen NS. Is there a health benefit of reduced tobacco consumption? A systematic review. Nicotine Tob Res 2007, 9: 631-646.

5 Anthonisen NR, Connett JE, Kiley JP, et al. Effects of smoking intervention and the use of an inhaled anticholinergic bronchodilator on the rate of decline of FEV1. The Lung Health Study. JAMA 1994; 272: 1497-1505.

6 Godtfredsen NS, Lam TH, Hansel TT, et al. COPD-related morbidity and mortality after smoking cessation: status of the evidence. Eur Respir J 2008; 32: 844-853.

7 Hughes JR. Effects of abstinence from tobacco: valid symptoms and time course. Nicotine Tob Res 2007; 9: 315-327.

8 Willemse BW, Postma DS, Timens W, et al. The impact of smoking cessation on respiratory symptoms, lung function, airway hyperresponsiveness and inflammation. Eur Respir J 2004; 23: 464-476.

9 Hoffmann D, Djordjevic MV, Hoffmann I. The changing cigarette. Prev Med 1997; 26: 427-434

10 Giskes K, Kunst AE, Benach J, et al. Trends in smoking behaviour between 1985 and 2000 in nine european countries by education. J Epidemiol Community Health 2005; 59: 395-401.

11 Ward MM, Swan GE, Jack LM. Self-reported abstinence effects in the first month after smoking cessation. Addict Behav 2001; 26 311-327.

12 Warner DO, Colligan RC, Hurt RD, et al. Cough following initiation of smoking abstinence. Nicotine Tob Res 2007; 9: 1207-1212.

13 Ussher M, West R, Steptoe A, et al. Increase in common cold symptoms and mouth ulcers following smoking cessation. Tob Control 2003; 12: 86-88.

14 Ussher M, West R, Evans $\mathrm{P}$, et al. Acute reduction in secretory immunoglobulin A following smoking cessation. Psychoneuroendocrinology 2004; 29: 1335-1340.
15 van Schayck CP, Halbert RJ, Nordyke RJ, et al. Comparison of existing symptom-based questionnaires for identifying COPD in the general practice setting. Respirology 2005; 10: 323-333.

16 Zielinski J, Bednarek M. Early detection of COPD in a high-risk population using spirometric screening. Chest 2001; 119: 731-736.

17 Price DB, Tinkelman DG, Halbert RJ, et al. Symptom-based questionnaire for identifying COPD in smokers. Respiration 2006; 73: 285-295.

18 Martinez FJ, Raczek AE, Seifer FD, et al. Development and initial validation of a self-scored COPD population screener questionnaire (COPD-PS). COPD 2008; 5: 85-95.

19 Freeman D, Nordyke RJ, Isonaka S, et al. Questions for COPD diagnostic screening in a primary care setting. Respir Med 2005; 99 1311-1318.

20 Internetworldstats.com. Internet Usage in Asia, 2009. www. internetworldstats.com/stats3.htm\#asia Date last updated: September 30, 2009. Date last accessed: March 23, 2009.

21 Yang G, Fan L, Tan J, et al. Smoking in China: findings of the 1996 national prevalence survey. JAMA 1999; 282: 1247-1253.

22 Walters N, Coleman T. Comparison of the smoking behaviour and attitudes of smokers who attribute respiratory symptoms to smoking with those who do not. Br J Gen Pract 2002; 52: $132-134$

23 Wilkes S, Evans A. A cross-sectional study comparing the motivation for smoking cessation in apparently healthy patients who smoke to those who smoke and have ischaemic heart disease, hypertension or diabetes. Fam Pract 1999; 16: 608-610.

24 Wang J, Etter JF. Administering an effective health intervention for smoking cessation online: the international users of stop-tabac. Prev Med 2004; 39: 962-968.

25 Etter JF, Le Houezec J, Perneger TV. A self-administered questionnaire to measure dependence on cigarettes: the cigarette dependence scale. Neuropsychopharmacology 2003; 28: 359-370.

26 Swiss Pulmonary League. Quel est votre risque de souffrir d'une BPCO? [What is your risk of suffering from COPD?]. www.lung ch/fr/test-bpco.html?no_cache=1 Date last accessed: March 18, 2010 .

27 Nunnally JC, Bernstein IH. Psychometric Theory. New York, McGraw-Hill, 1994

28 Chaudhuri R, Livingston E, McMahon AD, et al. Effects of smoking cessation on lung function and airway inflammation in smokers with asthma. Am J Respir Crit Care Med 2006; 174: 127-133.

29 von Hertzen L, Haahtela T. Signs of reversing trends in prevalence of asthma. Allergy 2005; 60: 283-292.

30 Cook C, Heath F, Thompson RL. A meta-analysis of response rates in web- or internet-based surveys. Educ Psychol Meas 2000; 60 821-836.

31 van der Molen T, Willemse BW, Schokker S, et al. Development, validity and responsiveness of the clinical COPD questionnaire. Health Qual Life Outcomes 2003; 1: 13. 